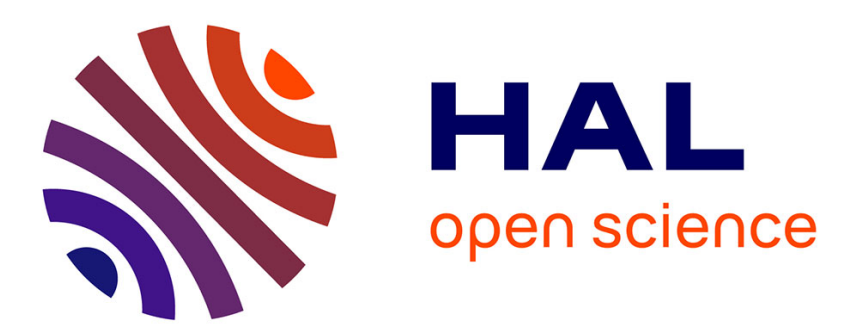

\title{
Building/City Information Model for Simulation and Data Management
}

\author{
T. Delval, A. Jolibois, S. Carré, S. Aguinaga, A. Mailhac, A. Brachet, J. \\ Soula, S. Deom
}

\section{- To cite this version:}

T. Delval, A. Jolibois, S. Carré, S. Aguinaga, A. Mailhac, et al.. Building/City Information Model for Simulation and Data Management. 12th European Conference on Product and Process Modelling (ECPPM 2018), Sep 2018, Copenhagen, Denmark. 10.1201/9780429506215 . hal-02201997v2

\section{HAL Id: hal-02201997 \\ https://hal-cstb.archives-ouvertes.fr/hal-02201997v2}

Submitted on 22 Aug 2019

HAL is a multi-disciplinary open access archive for the deposit and dissemination of scientific research documents, whether they are published or not. The documents may come from teaching and research institutions in France or abroad, or from public or private research centers.
L'archive ouverte pluridisciplinaire HAL, est destinée au dépôt et à la diffusion de documents scientifiques de niveau recherche, publiés ou non, émanant des établissements d'enseignement et de recherche français ou étrangers, des laboratoires publics ou privés. 


\title{
Building/City Information Model for Simulation and Data Management
}

\author{
T. Delval, A. Jolibois, S. Carré, S. Aguinaga, A. Mailhac, A. Brachet, J. Soula \\ CSTB (Centre Scientifique et Technique du Bâtiment), Paris, France
}

S. Deom

Paris La Défense, Nanterre, France

ABSTRACT: This publication is related to a research partnership between the CSTB (Centre Scientifique et Technique du Bâtiment) and the territorial administrative authority of Paris La Défense, regarding multiscale model management and interoperability processes. The project included several steps, starting with the semantization of building data but also information for infrastructures and street furniture. Then, a standard BIM urban model (or City Information Model) has been structured and enriched to address a set of simulations carried out on a pilot urban area. The research challenges were to define data dictionaries, pivotal models and replicable simulation methodologies using the CityGML format and then to integrate them through a multi-scale collaborative format into a database system. In that sense, the objective was to study the potential of BIM as a vector of simulations data for the urban scale.

\section{SCOPE OF WORKS: MODEL STRUCTURATION AND EXPERIMENTATION}

\subsection{Acquisition process}

An acquisition process starting from photogrammetry data has enabled the implementation of a BIM model on the entire territory through an interoperable format adapted to the urban area: the CityGML. The experiment focused on a spatial planning area extracted from the overall model, where urban challenges were expected by local authorities.

\subsection{Semantization process}

Our process aimed at automatizing the generation of the BIM model, without manual operations made from operators using CAD tools, which would be in any case almost impossible considering the mass of data to be processed on the territory. It consisted in translating topographical plan data into volumes and objects in the CityGML standard format. The achieved semantization allowed to assign a function to each part of the territory, as well as to cluster acquired meshes and forms into infrastructure objects such as roads, railways, green spaces and buildings and to structure them into the CityGML format (see in Figure 1).

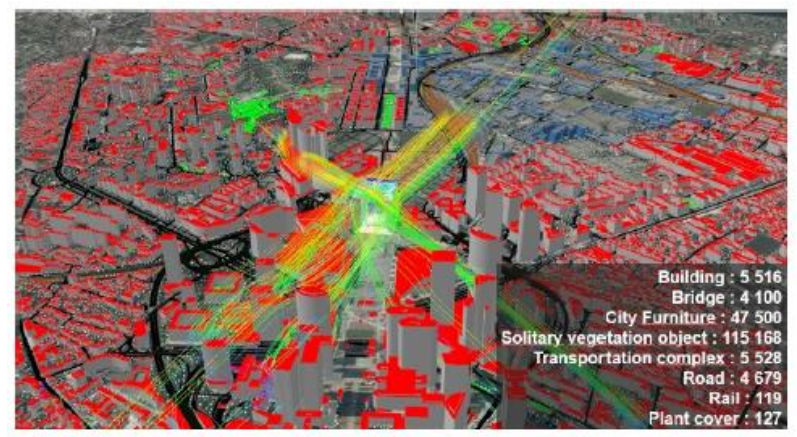

Figure 1. Partial view of the generated BIM model in CityGML format including CFD simulation results.

During the mesh acquisition process, infrastructure object groups integrated relevant information from the corresponding PostGIS spatial database. The first sketch, produced by the CSTB, has been stored in database using 3DCityDB solution. In this way, Paris La Défense was able to enrich it semantically (in particular adding generics attributes) and geometrically by usual SQL queries and GIS tools (QGis) before exporting it. The urban model has thus been enriched with structured information that can be requested and manipulated in the same way as the spatial GIS data from which it is derived (using for instance query or filtering), adding 3D volume properties to the BIM semantics. 


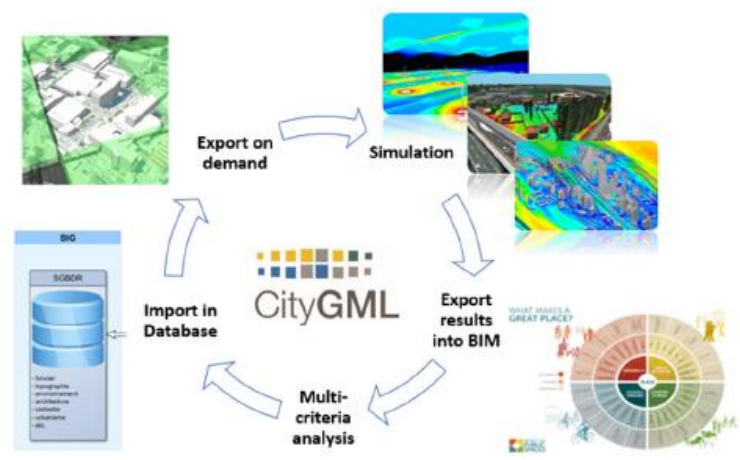

Figure 2. Schematic of the BIM simulation integrated process

\subsection{Implementation and experimentation results}

As stated above, the main objective of our research was to define an integrated BIM process (see in Figure 2) taking as an input a section of the territory, performing a set of simulations and returning the results within the same standard format. This process could allow storage of information (for Data Management through 3DCityDB) and could be used as an input for further simulations.

The first step was to structure and enrich the BIM model to address many simulations from interoperable formats. Our transversal research team - which included experts from several technical domains - carried out wind, acoustic and visual comfort simulations (including shadow and solar reflection simulation) in exterior spaces as well as LCA-based environmental evaluation of buildings. Creating and managing a "simulationready" model suited to all performed simulations represented a very challenging task, both from a scientific and technical standpoint. To achieve this, the CityGML format has been extended using extension mechanisms (ADE) as shown in Figure 3. Each extension was built thanks to a tight collaboration between a BIM expert and a simulation expert for each technical domain so as to be able to acquire and structure all required data, and to get the relevant geometrical description, this for each technical domain.

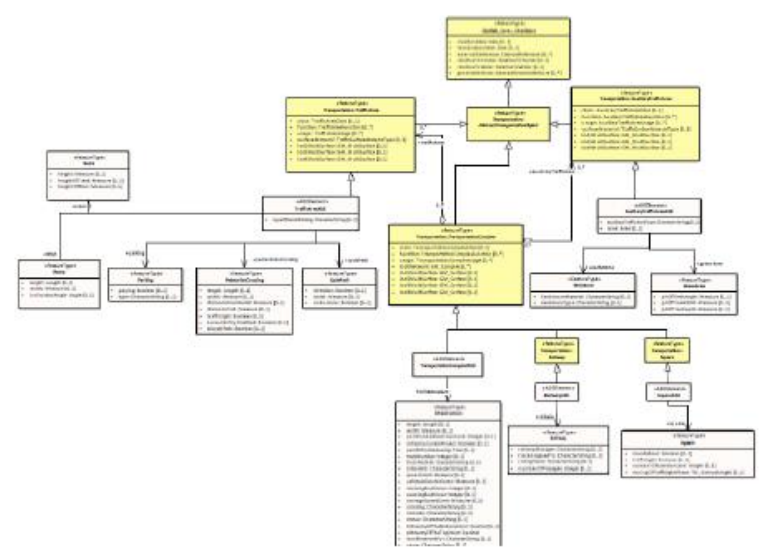

Figure 3: Example of Transportation Complex UML diagram developed for use of simulation.

One should point that our purpose is to be able to carry out the results within the OGC consortium to be exploited in future version of the standard. We now give some details about the way each simulation has been set up, run and integrated back into the CityGML database.

\section{ACOUSTIC SIMULATION}

\subsection{Preparing simulation from the BIM Model}

As noise exposure is still one of the main concerns for people annoyance and a well-documented cause for adverse health effects (World Health Organization 2011), one of the decided indicator to be calculated was average noise level. Several indicators are typically used in European and French noise regulations, including Lday (day-noise indicator), Lnight (nightnoise indicator) and Lden (day-evening-night noise indicator). For consistency with the European directive 2002/49/EC, we chose as an example to calculate the Lden, which is the specified indicator to assess overall annoyance.

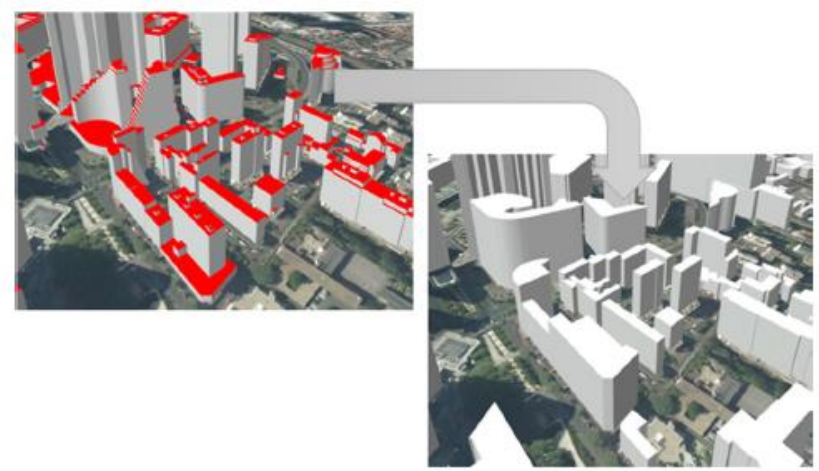

Figure 4. Application of the CityGML LOD2 to LOD1 transformation algorithm to buildings objects. 
To do so, the commercial software MithraSIG v5 (Geomod 2017), codeveloped by CSTB and the company Geomod, has been used. MithraSIG has been developed specifically to simplify as much as possible the integration of GIS data (which can be compared to CityGML LODO type data), and was recently extended as part of the European FP7 Holisteec project to directly integrate building objects from CityGML LOD1 files. This however required to develop a connector to automatically generate a LOD1 urban model from a LOD2 model (see in Figure 4), which is what was initially constructed in the BIM model.

To perform noise levels calculations, like all environmental noise software packages, MithraSIG requires several types of data:

- Topography (the ground), here defined as a triangulated complex surface part of a CityGML file

- Road traffic (road sections, traffic flow per section, rolling speed and percentage of heavy vehicles), defined as a set of polylines containing traffic flow attributes such as the Average Annual Daily Traffic (AADT) per section, here defined in a GIS (SHP) file

- Railway traffic (railway sections, number of passbys per section, rolling speed and type of train), defined as a set of polylines for the train tracks, but in which typical number of pass-bys and type of trains were added as attributes.

- Buildings (building ground coverages as polygons and building height as an attribute), which usually come from a GIS database, but here directly integrated from the LOD1 BIM model.

- Urban features, including vegetal areas (polygons, here defined as part of the ground CityGML file) and noise barriers (polylines with a height attribute, here defined in a GIS SHP file).

One should point out that for the calculation of the Lden, one needs to know how traffic conditions vary between the three periods of the day (day: $6 \mathrm{~h}$ 18h; evening: 18h-22h; night: $22 \mathrm{~h}-6 \mathrm{~h}$ ). Therefore, from average traffic indicators (such as the AADT), a typical distribution of traffic was applied.

Gathering all these data, a complete acoustic simulation model was generated (see Figure 5).

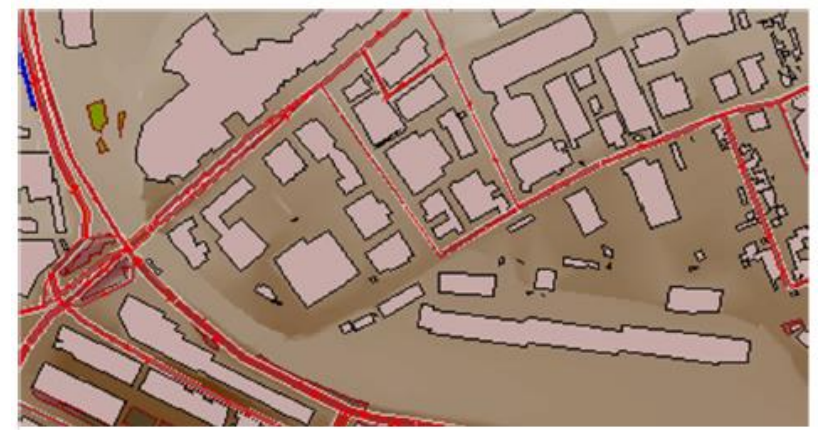

Figure 5. View of the MithraSIG acoustic simulation model one all relevant data were integrated.

\subsection{Results computing}

MithraSIG can generate several kinds of results, including: horizontal color maps (each color corresponding to a noise level interval), façade color maps, and calculation of a set of predefined points. To generate maps, MithraSIG runs a calculation on a mesh of points generated on the map.

To run the calculation, each road section or train track are divided into equivalent point sources, and ray propagation paths are calculated between each source and each receiver using a ray-tracing algorithm. Then, acoustic propagation effects (reflection, diffraction, geometric attenuation, etc.) for each path are calculated using the standard French method for noise mapping (NMPB'08). Finally, contributions of all paths to a given point are summed to get the level.

The acoustic simulation was first run over an entire neighborhood of Paris La Défense as a horizontal map (at height $1.5 \mathrm{~m}$ above the ground) with the following calculation parameters: $20 \mathrm{~m}$ receiver mesh size (yielding about 11400 calculation points); 2 reflections per path; $500 \mathrm{~m}$ maximum propagation distance; homogenous atmosphere. An example of generated Lden noise map in $\mathrm{dB}(\mathrm{A})$ is shown in Figure 6.

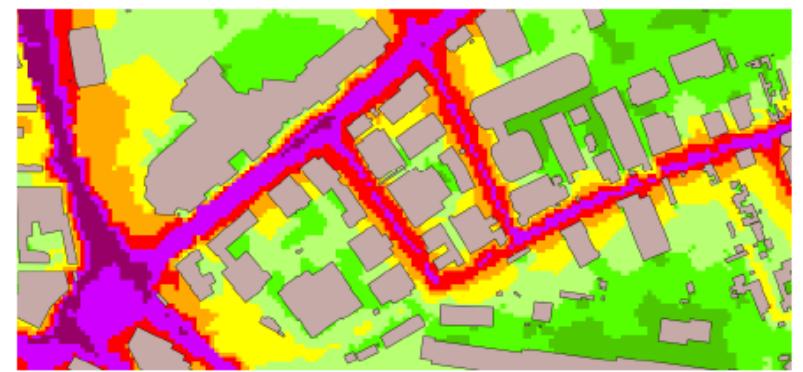

Figure 6: Generated Lden horizontal noise map. dB values vary between below 45 (deep green) to above 75 (deep purple). 
Other simulations were run in order to calculate noise exposure on building facades (see in Figure 7 , and on a set of predefined points (see in Figure 9) which was used in coordination with other simulations (see in section 6).

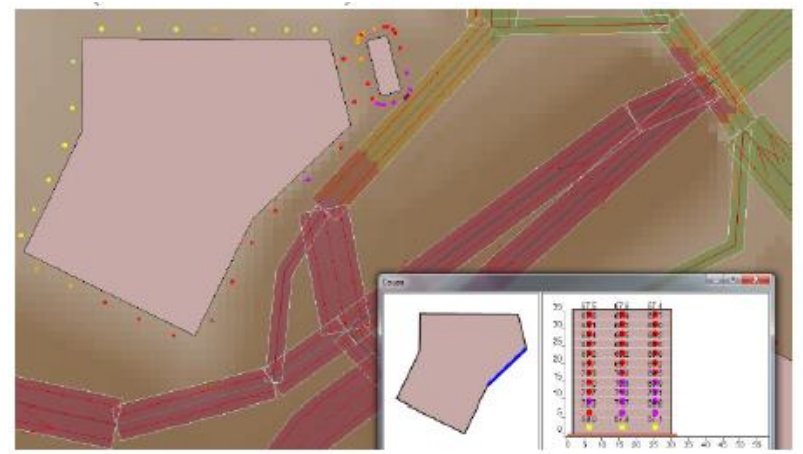

Figure 7: Example of building facade noise level calculation (same color code as above)

MithraSIG can export its calculation results in many different formats, including GIS type formats (SHP, etc.), PDF for graphical rendering, but also table-like formats (Excel, CSV, etc.) containing a list of objects with their identifiers and attributes values, such as calculated noise level. SHP files can contain polygons defining each colored area.

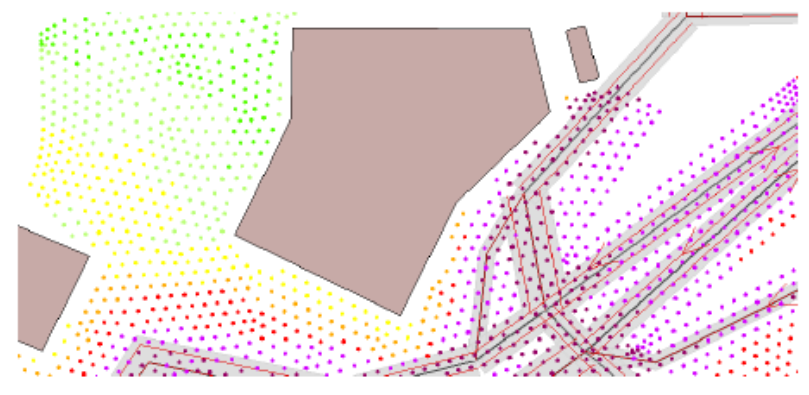

Figure 8: Noise level calculated on a set of predefined set of points (same color code as above).

Since one of the objectives was to re-integrate results into the BIM model, transformations were applied on color maps SHP files to integrate them into the BIM model, both for horizontal maps (see in Figure 9) and for buildings façades.

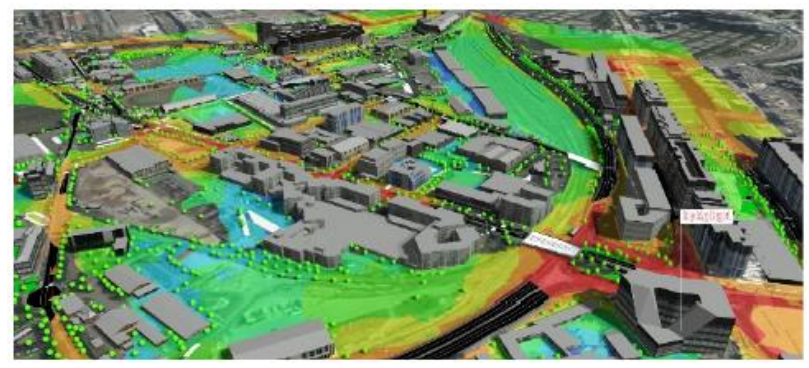

Figure 9. Integration of a horizontal noise map exported from MithraSIG as a SHP file into the BIM model.

\section{SOLAR COMFORT SIMULATIONS}

Regarding lighting issues, it was decided to focus the analysis on three subjects:

- shading analysis to qualify the impact of a development project on the nearby environment. It is therefore necessary to quantify the importance of solar losses / gains for public or private spaces.

- importance of solar reflections by glazed facades, which can induce significant glare risks.

- public lighting performance

\subsection{Preparing simulation from the BIM Model}

Expertise on artificial or natural lighting (sunshine) essentially requires $3 \mathrm{D}$ models of building surfaces and the environment as well as the knowledge of the photometric properties of relevant elements: artificial light sources, surface reflection factors, finer descriptions, spectral reflectance, brightness. Urban BIM models are therefore generally well adapted for this purpose, although it is necessary to choose the level of detail most suited to the required complexity (see Figure 10 ).

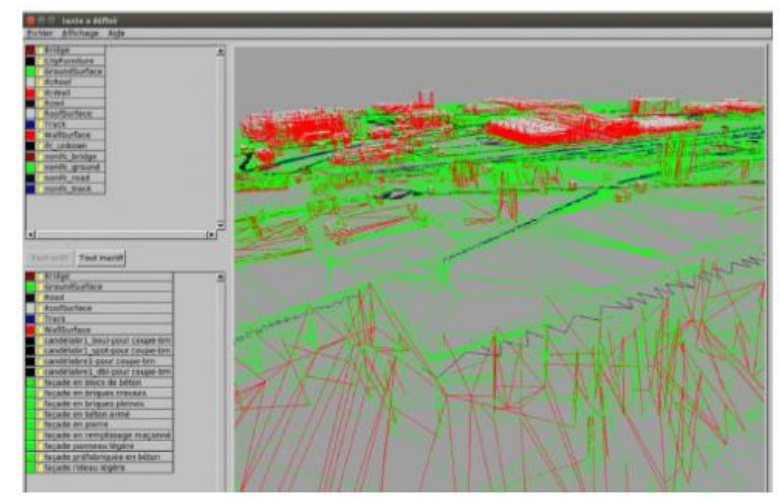

Figure 10. Example of a BIM model imported by Phanie (used lighting simulation software).

\subsection{Results computing}

For all lighting calculations, the software Phanie, developed by CSTB, has been used. It implements a path tracing method using adaptive records (Ribardière 2011).

The solar shadows analyses are performed on a set of areas of interest. These can be defined based on a list of geo-referenced coordinates or by 
exploiting various identifiers such as unique IDs of CityGML objects, CityGML types ("road", "wall", ...), or object groups associated with the same material. Then, the most synthetic mode of representation of the results is a map of the number of hours in the shade (or in the sun). This mapping is also available for each time step of the year, which allows for finer analyzes (generation of animations for a typical day for example).

The solar reflections analyses are also performed on a set of areas of interest that can be defined in the same way as for the analysis of solar shadows. The most synthetic mode of representation is a mapping of the number of hours in solar indirect lighting situation via specular elements. This mapping is also available for each time step of the year.

Finally, artificial lighting analyses are also performed on a set of areas of interest that can be defined in the same way as for the analysis of solar shadows. This time, the simplest representation is a map of lighting levels, calculated at a typical human height (see Figure 11).

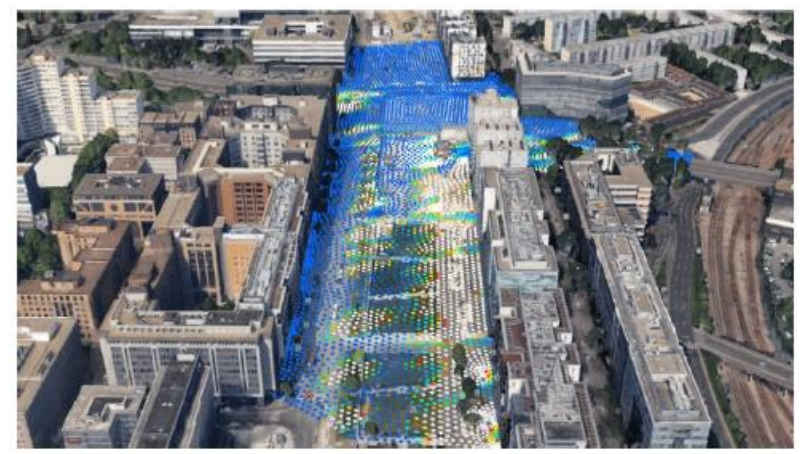

Figure 11. Map of lighting levels on a set of geo-referenced points

\subsection{Integration into the BIM model}

The calculated photometric quantities are accessible for various analyses and posttreatments (average values, transversal and longitudinal uniformities, etc.), from files with XML formalism. All this information is geo-localized, or even associated with identifiers of the BIM. They can thus enrich this model of various indicators (comfort, performance) and be represented by tools such as eveBIM or GoogleEarth. The BIM simplifies the definition of the areas of interest and integrates the notion of surface associated with each calculated photometric quantity. This mode of operation is particularly suited to solar studies and those relating to the artificial lighting of urban spaces (excluding roads). The definition of computing grids goes further because it meets normative requirements. For example, it makes it possible to calculate the longitudinal and transverse uniformities of the artificial lighting of the road. Its operation is, however, limited to small areas, which are supposed to be representative of an entire facility. More specific ADEs would be necessary to extend artificial lighting analyses.

\section{ENVIRONMENTAL SIMULATIONS}

\subsection{Preparing simulation from the BIM Model}

Two types of environmental simulations have been conducted at district scale: 1) Life-cycle assessment (LCA) and 2) calculation of a biodiversity potential: the biotope area factor (BAF).

Life-cycle assessment (LCA) is a method to assess environmental impacts associated with all the stages of a product's or service's life from raw material extraction through materials processing, manufacturing, distribution, use, repair and maintenance, and disposal or recycling. In the construction sector, LCA has been used since the 1990s to evaluate construction products and building and for few years its application has extended to urban scale, and is more and more used to assess urban precincts and building stocks at large scale (Mastrucci 2017).

In this study, ELODIE, the building LCA software developed by CSTB, has been used (ELODIE 2018). ELODIE is a collaborative tool for quantifying the environmental impacts over the entire life cycle of a building, or an urban object (infrastructure or street furniture).

Performing LCA at building and urban scale requires to collect large amount of information dataon the foreground system to complete the life cycle inventory $(\mathrm{LCI})$. The integration of BIM to building and urban LCA can reduce efforts during data acquisition, as well as allowing feedback of LCA results into BIM. As mentioned in section 1.3, the CityGML format has been extended using extension mechanisms (ADE) to provide "simulation-ready" model suited to all performed simulations. Regarding environmental simulations, propositions have been made to extend CityGML and ADE Energy standards for exchanging information for LCA simulation at 
urban scale. Detailed information is given in (Mailhac et al. 2017).

The biotope area factor (BAF) describe the proportion of surfaces favoring the biodiversity into an urban area. In a context of massive extinction, the integration of this indicator is a good way to use the BIM model to take into account the biodiversity conservation.

In the remainder of this section, main data requirements

for both LCA and CBS calculation are listed. To perform LCA at urban scale, urban objects within the physical boundaries of the urban project must be identified. This includes in particular:

- Buildings (including energy flows related to building consumption, during use);

- Public infrastructures: roads, cycle tracks, pedestrian paths, parking, railways; heat network; electricity network; drinking water network; sewage network; telecommunication network

- Urban furniture: benches, street lights, bus shelters, fences

Depending on the objective of the LCA study, and the data availability, a screening, simplified or complete/ detailed LCA approach can be applied (Wittstock 2012). In this study, the environmental assessment focuses on the elements listed above and consider a 50-year period for the district lifetime. All buildings within the project area are considered to be new construction (i.e. impacts related to their construction, use phase and end of life are taken into account). Data related to each object under study are collected (general information, materials and products used, quantitative data...) and stored in the BIM files.

The BAF expresses the ratio of the ecologically effective surface area to the total land area:

$B A F=\frac{\text { Ecologically- effective surface areas }}{\text { Total land area }}$

To calculate the BAF, the different surface's types of the urban area are identified and their areas are calculated thanks to information contained in BIM files. Then, each surface type is weighted according to its ecological value given by the (ADEME 2018), see Table 1.

\subsection{Results computing}

\begin{tabular}{|c|c|c|}
\cline { 2 - 3 } \multicolumn{1}{l|}{} & $\begin{array}{c}\text { Global warming } \\
\text { potential (kg eq } \\
\text { CO2) }\end{array}$ & \multicolumn{1}{c|}{} \\
\hline Buildings & $1.31 \mathrm{E}+09$ & $91 \%$ \\
\hline $\begin{array}{c}\text { o Construction products } \\
\text { and systems }\end{array}$ & $1.06 \mathrm{E}+09$ & $73 \%$ \\
\hline o Energy consumption & $2.54 \mathrm{E}+08$ & $18 \%$ \\
\hline Public infrastructures & $1.32 \mathrm{E}+08$ & $9 \%$ \\
\hline o Roads & $1.31 \mathrm{E}+06$ & $0 \%$ \\
\hline o Heat network & $6.34 \mathrm{E}+07$ & $4 \%$ \\
\hline o Electricity network & $2.10 \mathrm{E}+07$ & $1 \%$ \\
\hline o Drinking water network & $3.00 \mathrm{E}+07$ & $2 \%$ \\
\hline o Sewage network & $1.73 \mathrm{E}+06$ & $0 \%$ \\
\hline o Telecommunication & $1.50 \mathrm{E}+07$ & $1 \%$ \\
\hline Urban Furniture & $1.23 \mathrm{E}+06$ & $0 \%$ \\
\hline o Bench & $3.81 \mathrm{E}+04$ & $0 \%$ \\
\hline o Street lights & $9.29 \mathrm{E}+05$ & $0 \%$ \\
\hline o Bus shelters & $1.07 \mathrm{E}+04$ & $0 \%$ \\
\hline o Fences & $2.49 \mathrm{E}+05$ & $0 \%$ \\
\hline District "Les Groues" & $1.44 \mathrm{E}+09$ & $100 \%$ \\
\hline
\end{tabular}

Table 1. LCA results on the indicator Global warming potential ( $\mathrm{kg}$ eq $\mathrm{CO} 2$ ), for the entire district "les Groues"

Once foreground information on the district are collected in the BIM files, environmental impacts are calculated using Elodie and information from environmental databases that can be generic; such as Ecoinvent database (Ecoinvent 2018); or specific to the construction sector; such as the INIES database (French national reference database of environmental declarations for products, equipment, and services in the construction sector) (INIES 2017).

LCA results are a set of environmental indicators that reflect the environmental burden of the urban project. The results can be aggregated or presented for each life cycle phase of the project, or for each object. For convenience reasons, it has been decided to present in this paper results obtained only for the indicator " Global warming potential ", in kg eq. CO2 (see and Table 2). However, six other environmental categories have been calculated: hazardous waste disposed, nonhazardous waste disposed, total use of primary energy resources, net use of fresh water, photochemical ozone creation, and total use of nonrenewable primary energy resources (primary energy and primary energy resources used as raw materials).

In table 1 , results are presented for each object category and for the entire district considering a 
50-year period of analysis. Buildings account for more than $90 \%$ of the district's impact on global warming. However, one should remind that 1 ) results are based on hypotheses taken and 2) main objective of the simulation is to prove the feasibility of an environmental computation using BIM files.

\begin{tabular}{|c|c|c|c|}
\hline Surface type & $\begin{array}{l}\text { Area in Les } \\
\text { Groues }\left(\mathrm{m}^{2}\right)\end{array}$ & $\begin{array}{l}\text { Weighting } \\
\text { factor for } \\
\text { each sur- } \\
\text { face type }\end{array}$ & $\begin{array}{l}\text { Ecologi- } \\
\text { cally ef- } \\
\text { fective } \\
\text { surface } \\
\text { area }\left(\mathrm{m}^{2}\right)\end{array}$ \\
\hline Sealed & $1.08 \mathrm{E}+06$ & 0 & 0 \\
\hline Partially sealed & $2.36 \mathrm{E}+05$ & 0.3 & $7.07 \mathrm{E}+04$ \\
\hline Semi-open & $1.00 \mathrm{E}+05$ & 0.5 & $5.02 \mathrm{E}+04$ \\
\hline \multicolumn{4}{|l|}{ With vegetation: } \\
\hline $\begin{array}{l}\text { Unconnected to soil } \\
\text { (thickness }<80 \mathrm{~cm} \text { ) }\end{array}$ & $5.02 \mathrm{E}+04$ & 0.5 & $2.51 \mathrm{E}+04$ \\
\hline $\begin{array}{l}\text { Unconnected to soil } \\
\text { (thickness }>80 \mathrm{~cm} \text { ) }\end{array}$ & $6.45 \mathrm{E}+04$ & 0.7 & $4.51 \mathrm{E}+04$ \\
\hline Connected to soil & $5.27 \mathrm{E}+04$ & 1 & $5.27 \mathrm{E}+04$ \\
\hline $\begin{array}{l}\text { Rainwater infiltration } \\
\text { (per } \mathrm{m}^{2} \text { of roof area) }\end{array}$ & 0 & 0.2 & 0 \\
\hline $\begin{array}{l}\text { Vertical greenery up } \\
\text { to } 10 \mathrm{~m} \text { in height }\end{array}$ & 0 & 0.5 & 0 \\
\hline Greenery on rooftop & 0 & 0.7 & 0 \\
\hline \multicolumn{3}{|c|}{ Total ecologically effective surfaces $\left(\mathrm{m}^{2}\right)$} & $2.44 \mathrm{E}+05$ \\
\hline \multicolumn{3}{|c|}{ Total surface of the district $\left(\mathrm{m}^{2}\right)$} & $1.60 \mathrm{E}+06$ \\
\hline & $3 \mathrm{~A}$ & & 0.16 \\
\hline
\end{tabular}

Table 2. Intermediate results for the BAF

Regarding biodiversity potential of the district, the BAF result is a single score reflecting the ability of the urban project to welcome the biodiversity. The closer the factor is to 1 , the more favorable the site is to biodiversity. "Les Groues" district's BAF amount is 0.16 (intermediate results are presented in the Table 2). For this kind of area (central business facilities) a BAF at 0.30 should be reach as recommended in the city of Berlin (Senate Department for the Environment, 2018).

\section{AERAULIC SIMULATION}

\subsection{Preparing simulation from the BIM Model}

The purpose of the aeraulic simulations is to quantify the pedestrian comfort regarding the wind blowing between the buildings. To do so, it has been chosen to perform CFD (Computational Fluid Dynamics) simulations. They solve the Navier-Stokes equations on a discretized mesh representing the volume of air surrounding the buildings. The quality of the results of the simulations in very dependent of the quality of this mesh. The challenge is then to be able to extract a boundary surface from the CityGML suitable for CFD simulations as shown in the process Figure 12 .

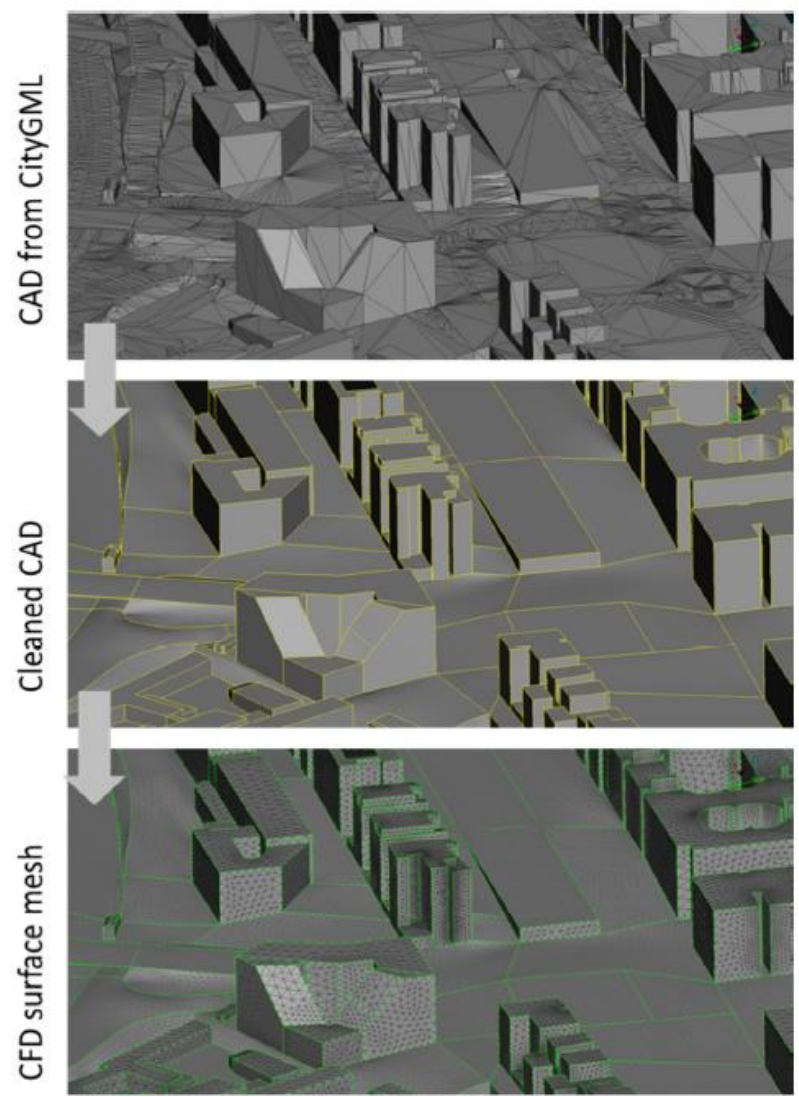

Figure 12. Illustration of the process to generate a correct CFD mesh from the CityGML model

This surface has indeed to be watertight and with a Level Of Detail adapted to the flow features at urban scales. As part of this work, an algorithm has been developed in order to simplify the geometry extracted from the CityGML, but a lot of "manual" operations remain to obtain a geometry compliant with CFD simulations. The LOD2 model which has been chosen was a good starting point regarding flow features, however some details are yet to be removed from the geometry to limit the number of cells in the mesh. Finally, the most difficult task is to connect the building geometry with the ground surface to make a single watertight boundary. Once the "cleaned" geometry has been obtained, it must be meshed. As the pedestrian comfort is monitored at $1.5 \mathrm{~m}$ from the ground, it is important to have a so-called "boundary layer" mesh which allows a good resolution of the flow near the ground surface (see in Figure 13). 


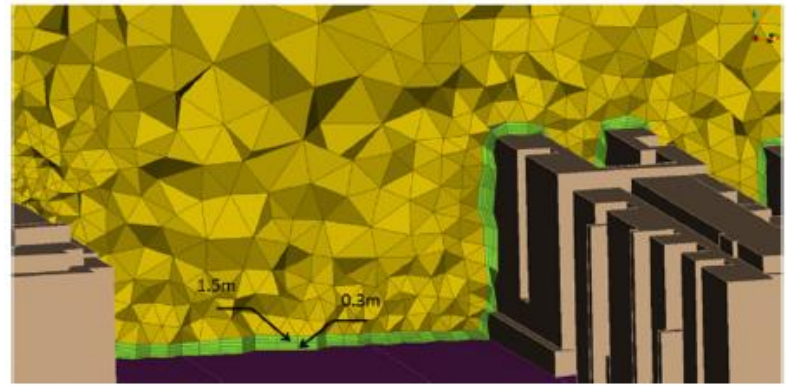

Figure 13. View of a vertical cut of the CFD mesh with a focus on the boundary layer mesh.

\subsection{Results computing}

Simulations have been carried out using the so called steady RANS (Reynolds Average Navier Stokes) approach. It solves the averaged flow and uses turbulence models which mimic the impact of the unsteady part of the flow on the mean flow. A k-epsilon realizable model is used. The RANS approach proposes the most efficient ratio between confidence in the results and computational time. Simulations are ran using the open source CFD code OpenFOAM.

The flow is solved for 18 wind directions (from $0^{\circ}$ to $360^{\circ}$ with $20^{\circ}$ steps), an example of the wind flows for directions $40^{\circ}$ and $240^{\circ}$ is shown Figure 14. A boundary layer profile is prescribed at the inlet of the simulations. This profile is relevant of the density of the surrounding urban area according to the Eurocode regulation. Special boundary conditions on the ground (rough walls) are used in order to maintain this boundary layer profile all over the simulations.

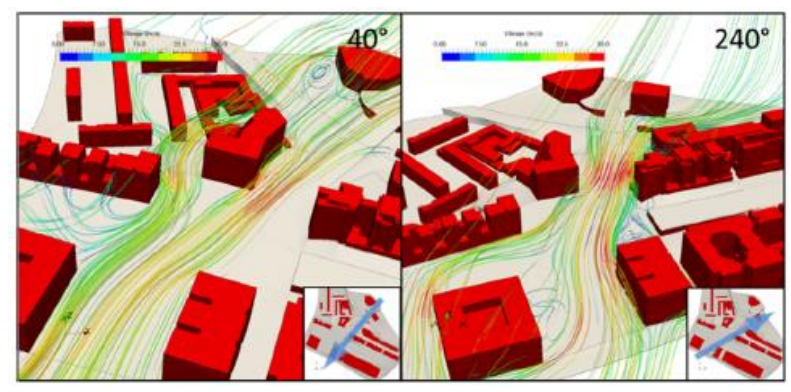

Figure 14: Examples of flow features for two wind directions

For each wind directions the wind at pedestrian level $(1.5 \mathrm{~m})$ is measured and compared to the wind speed prescribed at the inlet of the simulation, which is also relevant of the wind speed which is measured at a local weather station. It is then possible to calculate a "transfer function" between the wind speed measured at the weather station and the wind speed all over the urban area. The wind statistics of the weather station can be then extrapolated to every single point of the simulation.

A quantitative comfort criterion is then defined. It is based on the probability of the wind speed exceeding $3.6 \mathrm{~m} / \mathrm{s}$. This "discomfort frequency" shall not exceed a given value depending of the usage of the area. For example, for a restaurant terrace, it shall not exceed $2 \%$, for a strolling area $10 \%$.

\subsection{Integration into the BIM model}

The results of the simulations provide a map of this comfort criterion all over the pedestrian area. This data is then helpful to assess the impact of modifications of the urban area on the pedestrian wind comfort. Those maps are then directly inserted inside the BIM model (see Figure 15). It is also possible to insert some ribbons drawn from the CFD results which picture the flow behavior between the buildings. These ribbons are then helpful to understand the origin of comfort issues and to design corrective devices. For example, in dense areas with high rise buildings, it is not uncommon to see comfort issues induced by streams of wind collected at the top of the tower and sent toward the ground. This can be solved using wind barriers or tall vegetation.

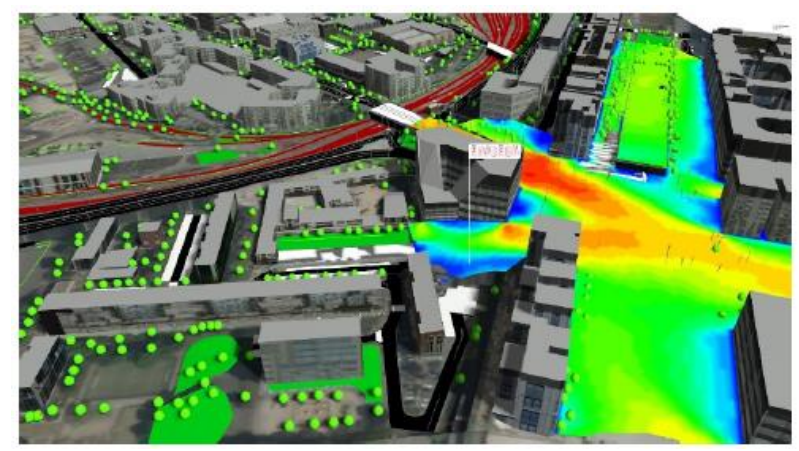

Figure 15: Pedestrian wind comfort map inserted in the BIM model

\section{AGREGATION INTO BIM DATA}

\subsection{Results computing}

Although directly displaying simulation results (like noise or pressure maps) allows some form of analysis, the issue of storage and cross-analysis is still a key issue which our work tried to address. The proposed approach was to store all results as BIM data in the same CityGML format as the input 
data. Multi-disciplinary analysis was then made possible thanks to the development of a generic colorization tool in order to display any type of CityGML object attributes in agreement with attribute values.

To apply this idea, a set of "sensor" points were generated (from a CFD meshing tool) and given as input for all simulations. This set constituted a common basis on which all simulations above were performed (see in sections 2 to 5 ).

Once all simulations results were generated, the sensor points were integrated into the BIM model. They were structured in the form of City-Furniture objects of implicit geometry, which means that each point geometry was an instanced parallelepiped. The geometry is thus stored only once and then replicated when displayed on all points. Files containing results are thus very light since they only contain point coordinates and values coming from the different simulations (see in Figure 16).

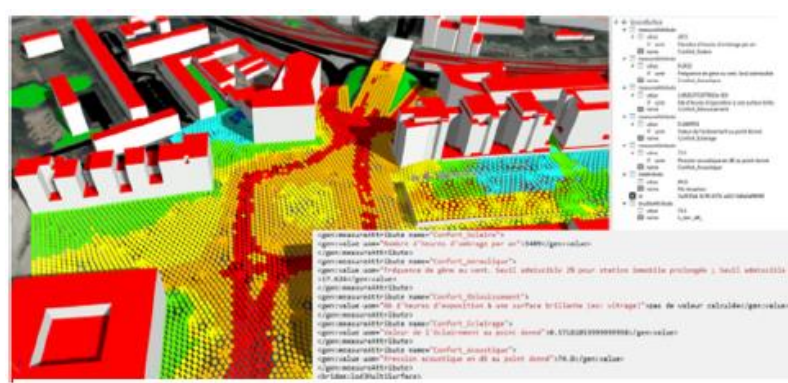

Figure 16. Aggregation of simulation results into data points defined as City Furniture Objects into the CityGML model.

\subsection{Future Works}

The next objective of our research is to design a decision support tool for the analysis of public spaces overall quality. The main feature of this tool would be to combine the results of physical simulations, statistical data and socio-urban approaches into a set of key performance indicators.

Besides, our social scientists and the administrative authority in charge of urban strategy are working on innovative user-centric approaches for urban planning and on ways of translating urban quality criteria into BIM standards.

\section{REFERENCES}

ADEME. Le coefficient de biotope par surface (CBS).

http://multimedia.ademe.fr/catalogues/CTecosys temes/fiches/outil11p6364.pdf >, Accessed 18-042018

" The Ecoinvent Database ". < https://www.ecoinvent.org/ >, Accessed 18-042018.

" ELODIE Le logiciel de la performance globale des bâtiments ". < http://version3.elodie-cstb.fr/ >, Accessed 18-04-2018.

Geomod 2017. Release of MithraSIG v5 software. $<\quad$ http://en.geomod.net/gmd-societe-en/gtaccueil/gt-logiciels-2/mithrasuite/mithrasig/ > .

" INIES | Les données environnementales et sanitaires de référence pour le bâtiment " .< http://www.inies.fr/accueil/>, Accessed 27-062017.

Mailhac, A., Cor, E., Vesson, M., Rolland, E., Schiopu, N., Schetelat, P., \& Lebert, A. (2017). A proposition to extend CityGML and ADE Energy standards for exchanging information for LCA simulation at urban scale. Presented at the Life Cycle Management Conference, September 2017 Luxembourg

Mastrucci A., A. Marvuglia, U. Leopold, et E. Benetto, Life Cycle Assessment of building stocks from urban to transnational scales: A review, Renew. Sustain. Energy Rev., vol. 74, p. 316-332, juill. 2017.

Senate Department for the Environment. A green city center - BAF. < https://www.berlin.de/senuvk/umwelt/landschaf tsplanung/bff/en/anwendungsbereiche.shtml >, Accessed 20-04-2018.

Ribardière M., Carré S., Bouatouch K. (2011). Adaptive Records for Irradiance Caching. Computer Graphics Forum 30(6):1603-1616. September 2011.

Wittstock B., et al., EEBguide Operational Guidance for Life Cycle Assessment Studies of the Energy Efficient Buildings Initiative, 2012, Available on http://www.eebguide.eu/

World Health Organization 2011. Burden of disease from environmental noise 